\title{
Indução da ovulação em vacas com gonadotrofina coriônica humana (hCG) purificada por cromatografia de afinidade
}

Claudia Maria BERTAN ${ }^{1}$ Marcelo CERQUEIRA CESAR $^{2}$

Silvana Marina Picolli

PUGINE ${ }^{2}$

Mario BINELLI ${ }^{1}$

José Antonio VISINTIN ${ }^{1}$

Mayra Elena Ortiz D'Avila

ASSUMPÇÃO ${ }^{1}$

\section{Correspondência para:}

CLÁUDIA MARIA BERTANI Centro de Biotecnologia em Reprodução Animal

Departamento de Reprodução Animal

Faculdade de Medicina Veterinária e

Zootecnia

Universidade de São Paulo

Av. Duque de Caxias Norte, 225

13630-000 - Pirassununga-SP

binelli@usp.br

Recebido para publicação: 06/07/2004 Aprovado para publicação: 01/06/2005

\begin{abstract}
1 - Departamento de Reprodução Animal da Faculdade de Medicina
Veterinária e Zootecnia da Universidade de São Paulo, Pirassununga - SP

2 - Departamento de Ciências Básicas da Faculdade de Zootecnia e

Engenharia de Alimentos da Universidade de São Paulo, Pirassununga - SP
\end{abstract}

Palavras - chave: Gonadrotofina coriônica humana (hCG). Cromatografia. Concavalina-A. Ovulação. Vacas.

de Concanavalina-A Sepharose (Con-A) foi equilibrada e cem mil unidades internacionais (UI) de Pregnyl® foram aplicadas na coluna. Frações de $3,8 \mathrm{~mL}$ foram colhidas $\left(4^{\circ} \mathrm{C}\right)$ a cada 5 minutos durante 12,5 horas, resultando em um total de 150 frações. Após a fração 76 adicionou-se à coluna solução tampão contendo $0,3 \mathrm{M}$ de $\alpha-$ metilglicosidase. A concentração protéica das frações foi estimada por espectrofotometria $(280 \mathrm{~nm})$. Foram observados dois picos de absorbância, um entre as frações 14 e 19 e outro entre as frações 90 e 100. As frações 14 a 19 e 90 a 150 foram reunidas seqüencialmente aos pares, concentradas por ultrafiltração e analisadas por SDS-PAGE. O primeiro pico resultou da eluição das proteínas não adsorvidas pela matriz de Con-A, enquanto o segundo representou as proteínas adsorvidas pela coluna, especialmente o hCG. As frações contendo hCG foram reunidas em uma única amostra cuja concentração protéica foi quantificada pelo método de Lowry. Vacas no $5^{\circ}$ dia de um ciclo estral sincronizado, apresentando um folículo dominante maior que $8 \mathrm{~mm}$ de diâmetro, foram injetadas com $0,1,0,2$ ou $0,3 \mathrm{mg}$ de proteína contida na amostra purificada. Após 48 horas, a taxa de ovulação observada foi de $0 \%, 50 \%$ e $75 \%$, respectivamente. Foi demonstrado no presente estudo que a técnica de cromatografia por afinidade foi eficiente para aumentar a concentração relativa do hCG preservando sua atividade biológica.

\section{Introdução}

Vários estudos foram conduzidos em fêmeas bovinas com a administração do hCG em diferentes momentos do ciclo estra $1,2,3,4,5,6,7,8,9,10,11,12,13,14$. Nestes estudos, verificou-se que o hCG desempenha uma atividade semelhante à do $\mathrm{LH}$, promovendo à ovulação do folículo dominante, a formação de um corpo lúteo acessório e o aumento das concentrações plasmáticas de progesterona. Thatcher et al. ${ }^{15}$ observaram que a ovulação do folículo dominante pelo
hCG foi obtida com êxito entre o $4^{\circ}$ e $7^{\circ} \mathrm{e}$ o $14^{\circ}$ e $16^{\circ}$ dias do ciclo estral.

O hCG é um hormônio glicoproteíco heterodimérico, formado pela associação não covalente da subunidade â $(23 \mathrm{kDa}) \mathrm{com}$ a subunidade á $(35 \mathrm{kDa})$, segundo Pierce e Parsons ${ }^{16}$. O hCG é secretado pelas células trofoblásticas em mulheres gestantes e tem uma ação agonista aos receptores de LH, sendo responsável pela manutenção do corpo lúteo e pela síntese de progesterona necessária para manter a gestação ${ }^{17}$.

O procedimento de purificação do 
hCG utilizando cromatografia por afinidade em Concanavalina-A Sepharose (Con-A) foi descrita por Manjunath e Sairam ${ }^{18}$. Aproveitando-se da afinidade de ligação do hCG à Con-A torna-se possível aumentar a concentração relativa de hCG a partir de uma amostra complexa. Nessa técnica, a Con-A atua como o "ligante" da matriz, por apresentar uma alta especificidade de ligação ao hCG. Quando uma amostra contendo diferentes proteínas é aplicada na coluna e passa através da matriz, o hCG éimediatamente ligado à Con-A, enquanto as demais proteínas passam livremente pela coluna, sendo eluídas juntamente com a solução tampão, ocasião em que se estabelece a separação do hCG das demais proteínas contidas na amostra inicial. Posteriormente, a aplicação de uma solução contendo $\alpha$-metilglicosidase possibilita o desligamento do hCG da matriz de Con-A, promovendo a eluição e a recuperação do hCG nas frações subseqüentes.

A utilização de técnicas de cromatografia pode causar uma redução na atividade biológica da proteína isolada. A atividade biológica de um determinado hormônio é mensurada pela capacidade do mesmo em exercer um determinado efeito biológico que possa ser quantificado. Vários ensaios biológicos foram descritos para quantificar a atividade biológica do hCG em ratas(os) e camundongas (os) impúberes ${ }^{19,20,21,22,23,24,25,26}$. Bertan, Cunha e Binelli ${ }^{27}$ demonstraram que tais ensaios foram ineficientes e pouco sensíveis.

Considerando-se a capacidade do hCG em promover a ovulação de folículos $\geq 8 \mathrm{~mm}$ em vacas no $5^{\circ}$ dia do ciclo estral ${ }^{3,4,7,11,12,28}$ esse estudo objetivou: (1) aumentar a concentração relativa do hCG a partir de uma preparação comercial (Pregnyl® - Organon) utilizando a técnica de cromatografia de afinidade em ConA Sepharose e (2) avaliar a capacidade ovulatória da amostra purificada.

\section{Materiais e Métodos}

PURIFICAÇ̃̃o Do hCG POR CROMATOGRAFA DE AFINIDADE UTIUZANDO Con-A Sepharose

A técnica de cromatografia de afinidade, utilizando a matriz de Con-A Sepharose, foi realizada na Universidade de São Paulo, na Faculdade de Zootecnia e Engenharia de Alimentos, no Departamento de Ciências Básicas, no Laboratório de Bioquímica, no campus de Pirassununga -SP. A técnica utilizada foi a descrita por Manjunath e Sairam ${ }^{18}$ com algumas modificações.

\section{Cromatografia}

Uma coluna de vidro $1,6 \times 28 \mathrm{~cm}$ (Amersham Biosciences) foi preenchida com uma matriz de Con-A Sepharose (Amersham Biosciences). A coluna foi equilibrada com $500 \mathrm{~mL}$ de solução tampão 1 (Tris- $\mathrm{HCl} 20 \mathrm{mM}$ $\mathrm{pH} 7,4 ; \mathrm{NaCl} 0,5 \mathrm{M}$ e NaN 3 0,02\%). Cem mil unidades internacionais (UI) de hCG (Pregnyl® -Organon) foram diluídas em $1300 \mu \mathrm{L}$ da solução tampão 1 e aplicadas na coluna. Foram coletadas frações de $3,8 \mathrm{~mL}$ a cada 5 minutos, durante 12,5 horas, resultando em um total de 150 frações. A solução tampão inicial foi eluída até a fração 76 sendo então substituída por uma solução tampão 2, constituída pela solução tampão 1 acrescida de $0,3 \mathrm{M}$ de $\alpha$-metilglicosidase. Todo o procedimento de cromatografia foi realizado a $4^{\circ} \mathrm{C}$.

\section{Espectrofotometria e concentração das amostras}

A concentração protéica das frações foi estimada por espectrofotometria $(280 \mathrm{~nm})$. As frações contendo proteínas foram seqüencialmente reunidas aos pares e concentradas por ultrafiltração (Millipore Filtro Centricon - massa molecular de exclusão $10 \mathrm{kDa}$ ), a $4.000 \mathrm{x}$ g, durante 30 minutos, a $4^{\circ} \mathrm{C}$. O volume referente a duas frações $(7,6 \mathrm{~mL})$ após ultrafiltração foi reduzido para aproximadamente $220 \mu \mathrm{L}$.

\section{Eletroforese e coloração com nitrato de prata}

As frações concentradas foram analisadas por eletroforese em gel redutor de poliacrilamida (12\%). As amostras aplicadas em cada poço continham $1,25 \mu \mathrm{L}$ da amostra concentrada, $8,75 \mu \mathrm{L}$ de água destilada e desionizada e $10 \mu \mathrm{L}$ do corante da amostra (6,25mM Tris- $\mathrm{HCl} \mathrm{pH}$ 6.8; SDS 4\%; glicerol 20\%; Bromofenol Blue 0,05\% e $\beta$-mercaptoetanol 10\%). A eletroforese foi 
realizada a $200 \mathrm{~V}, 100 \mathrm{~mA}$, durante 55 minutos. Os géis foram corados com nitrato de prata (RSK1 Sigma - Rapid Silver Staining Kit) e as frações contendo hCG foram identificadas. Estas foram reunidas em uma única amostra e a quantidade de proteínas foi determinada pelo método de Lowry. A amostra foi liofilizada e armazenada a $4^{\circ} \mathrm{C}$ em dessecador até a realização do ensaio biológico.

verificação da atividade biológica do hCG purificado em fêmeas bovinas multíparas

Local do Experimento e Animais

Esse teste foi realizado na Universidade de São Paulo, na Faculdade de Medicina Veterinária e Zootecnia, no Centro de Biotecnologia em Reprodução Animal, no Laboratório de Fisiologia e Endocrinologia Molecular, no campus de Pirassununga - SP. Foram utilizadas onze vacas holandesas, não lactantes, com condição corporal 3,5 a 4,5 (escala de 1 a 5, segundo Richards, Spitzer e Warner $\left.{ }^{21}\right)$, no $5^{\circ}$ dia do ciclo estral (considerando o estro como dia zero do ciclo).

\section{Delineamento Experimental}

Os estros foram sincronizados com a inserção e manutenção de um dispositivo intravaginal contendo progesterona (CIDR®- PFIZER) durante 7 dias juntamente com uma injeção de um análogo sintético do GnRH (Lecirrelina - N.C. Gestran ${ }^{\circledR}$ - Syntex). Na retirada do CIDR foram aplicadas $150 \mu \mathrm{g}$ de D- cloprostenol (N.C. Preloban ${ }^{\circledR}-$ Intervet). Os estros foram observados duas vezes ao dia e as vacas foram divididas de acordo com o escore corporal em três grupos. No $5^{\circ}$ dia do ciclo estral, as vacas foram examinadas por ultrasonografia e as que apresentaram um folículo $\geq 8 \mathrm{~mm}$ receberam $0,1 \mathrm{mg}(\mathrm{n}=3)$, 0,2mg $(\mathrm{n}=4)$ ou $0,3 \mathrm{mg}(\mathrm{n}=4)$ de proteína total contida na amostra purificada de hCG, via intramuscular. Considerou-se como ovulação o desaparecimento do folículo dominante $\geq 8 \mathrm{~mm}$ presente no ovário no $5^{\circ}$ dia do ciclo estral em exame ultrasonográfico realizado 48 horas após a injeção da amostra purificada contendo hCG.

\section{Resultados e Discussão}

As absorbâncias das frações coletadas durante a técnica de cromatografia de afinidade estão representadas na Figura 1. A presença do hCG nas frações avaliadas foi determinada pela presença de bandas de peso molecular semelhantes às apresentadas por uma amostra de hCG padrão (Sigma) na Fig. 2, Linha 2, correspondentes às subunidades a e $\beta$. O hCG é uma glicoproteina heterodimérica, constituída por subunidades $\alpha$ e $\beta$, com pesos moleculares de aproximadamente $23 \mathrm{kDa}$ e $35 \mathrm{kDa}$, respectivamente. $\mathrm{O}$ uso de um gel desnaturante causou a separação das subunidades a e $\beta$ do hCG, representadas no gel por duas bandas.

O primeiro pico de absorbância registrado entre as frações 14 e 19, foi representado na Figura 2 pelas linhas 3, 4 e 5. Foram observadas bandas de vários pesos moleculares, entretanto, não foram observadas bandas com pesos moleculares correspondentes às subunidades que constituem o hCG $(23 \mathrm{kDa}$ e $35 \mathrm{kDa})$. Sugerese a partir desses resultados que o aumento de absorbância nessas frações resultou da eluição de proteínas contidas na amostra inicial não adsorvidas pela matriz de Con$\mathrm{A}$, e que houve uma eficiente ligação e retenção do hCG à matriz de Con-A, uma vez que o hCG não estava presente nessas frações.

As frações correspondentes ao segundo pico de absorbância observadas entre as frações 89 e 100, estão representadas na Figura 2 pelas linhas 6, 7, 8, 9, 10, $11 \mathrm{e}$ 12. O segundo pico de absorbância foi representado por proteínas eluídas da matriz, após a adição de $\alpha$-metilglicosidade, especialmente o hCG. O intervalo entre a adição da $\alpha$-metilglicosidase e a eluição do hCG ocorreu após a passagem do tampão em quantidade correspondente ao volume 


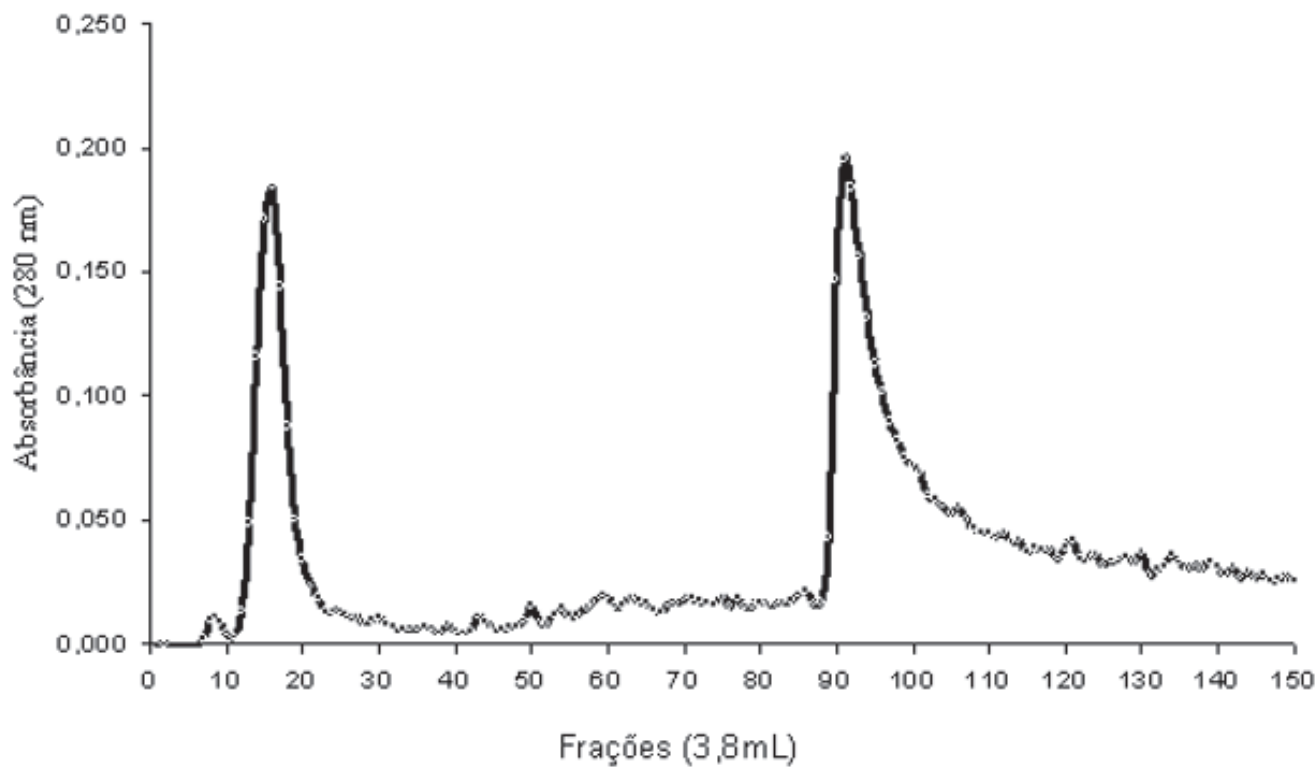

Figura 1 - Absorbância das frações coletadas durante cromatografia por afinidade do produto comercial Pregnyl?
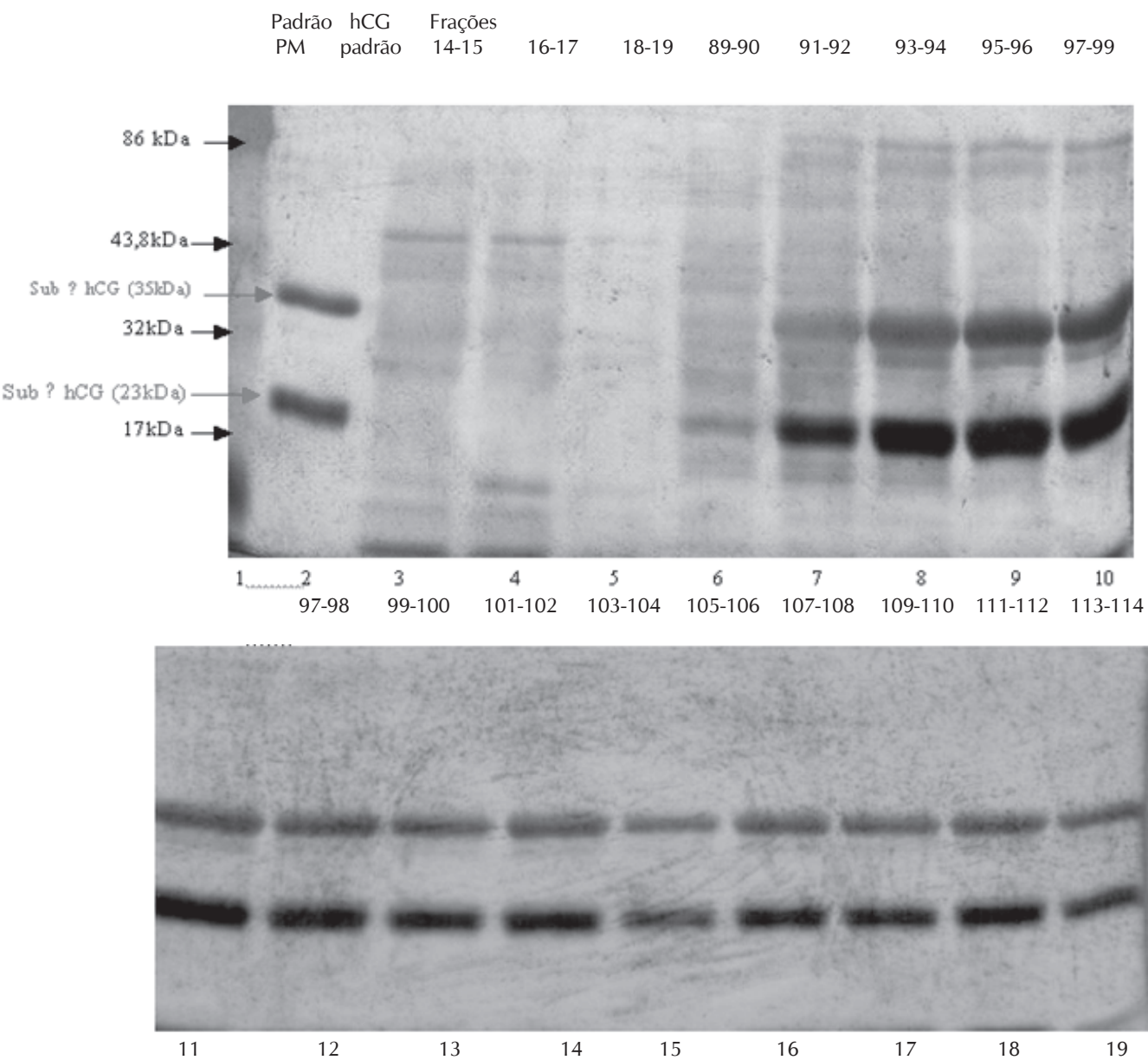

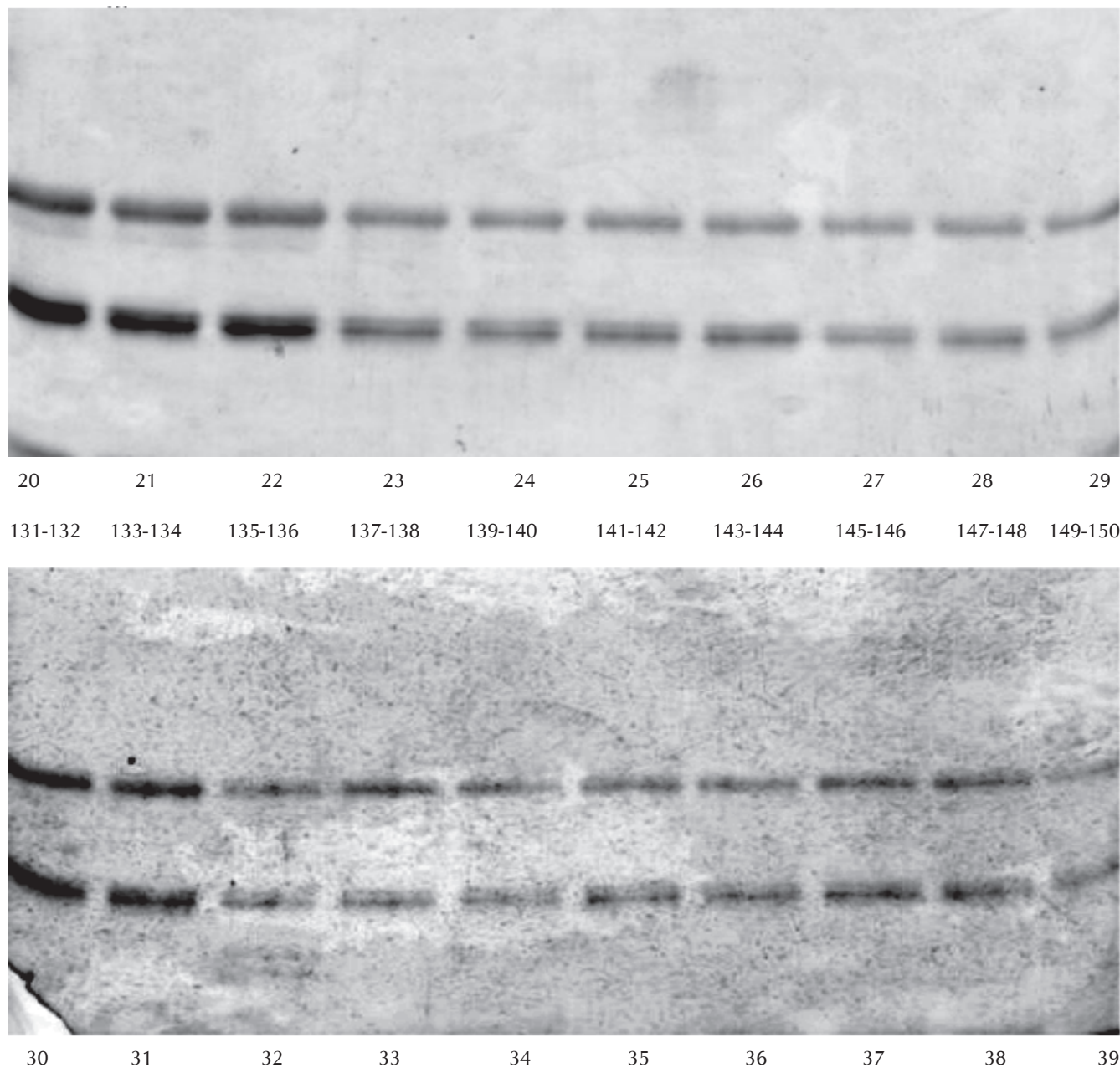

Figura 2 - Caracterização das proteínas contidas nas frações obtidas por cromatografia de afinidade. Frações foram concentradas e analisadas por SDS-PAGE (12\%) e coloração por nitrato de prata. Linhas (1) Padrão de peso molecular (2) hCG puro Sigma (3) Frações (F): $14-15$ (4) F 16-17 (5) F 18-19 (6) F 89-90 (7) F 91-92 (8) F 93-94 (9) F 95-96 (10) F 97-98 (11) F 97-98 (12) F 99-100 (13) F $101-102$ (14) F 103 104 (15) F 105-106 (16) F 107-108 (17) F 109-110 (18) F 111-112 (19) F 113-114 (20) F 113-114 (21)F 115-116 (22) F 117-118 (23) F 119-120 (24) F 121-122 (25) F 123-124 (26) F 125-126 (27) F 127-128 (28) F 129-130 (29) F 131-132 (30) F 131-132 (31) F133134 (32) F 135-136 (33) F 137-138 (34) F 139-140 (35) F 141-142 (36) F 143-144 (37) F 145-146 (38) F 147-148 (39) F $149-150$

total da coluna.

A eluição do hCG ligado à Con-A pela $\alpha$-metilglicosidade ocorreu de maneira lenta e contínua, uma vez que o mesmo encontrou-se presente nas frações 91 a 150 (Figura 2, linhas 7 a 39). O perfil de liberação foi idêntico ao descrito por Manjunath e Sairam ${ }^{18}$, onde após a adição da $\alpha$ metilglicosidase a eluição do hCG ocorreu nas 60 frações subseqüentes. Aqueles autores utilizaram o mesmo volume $(3,8 \mathrm{~mL})$ e fluxo utilizado no presente estudo.

Embora nas primeiras frações eluídas houvesse grande quantidade de hCG também houve a presença de contaminantes (frações 91 a 98). Nas frações subseqüentes houve a eluição do hCG praticamente isento de contaminantes (frações 99 a 150). Diante desses resultados reuniram-se as frações 99 a 150, que foram administradas nas vacas em três diferentes quantidades.

Usualmente, para a purificação do 
hCG, a partir de amostras comerciais, preconiza-se a utilização da técnica de cromatografia por afinidade utilizando a Con-A, sendo a amostra purificada submetida a uma segunda técnica de cromatografia, a filtração em gel, para a separação de proteínas por peso molecular. No presente estudo, a utilização de uma única técnica de cromatografia, com algumas modificações em relação à técnica de Manjunath e Sairam ${ }^{18}$, foi suficiente para a obtenção de uma amostra purificada.

A taxa de ovulação nos animais tratados, 48 horas após a administração da amostra purificada, foi de $0 \%, 50 \%$ e $75 \%$ para as vacas tratadas respectivamente com $0,1 \mathrm{mg}, 0,2 \mathrm{mg}$ e $0,3 \mathrm{mg}$ de proteína contida na amostra purificada contendo hCG. Marques et al. ${ }^{19}$ verificaram que a ovulação em vacas tratadas com hCG ocorreu até 36 horas. Assim, a constatação da ovulação verificada 48 horas após a administração do hCG foi adequada para avaliar a ovulação ou não do folículo dominante.

Demonstrou-se que o hCG desempenha uma atividade semelhante à do $\mathrm{LH}$, promovendo à ovulação do folículo dominante, a formação de um corpo lúteo acessório e o aumento das concentrações plasmáticas de progesterona em vários momentos do ciclo estral. O hCG promoveu a ovulação do folículo dominante da primeira onda nos dias $4^{1,2}, 5^{3,4,7,11,12}, 6^{6}$, $7^{2,5}, 8^{19}, 10^{2}$ e dias 14 a $16^{1}$ do ciclo estral. Verificou-se que o folículo dominante adquire receptores para LH ou a expressão do gene para o receptor de LH somente 2 a 4 dias depois da emergência da onda folicular quando atinge de 8 a $10 \mathrm{~mm}$ de diâmetro ${ }^{30,31}$, assim, no dia 5 do ciclo estral, as vacas possuem um folículo dominante $(\geq 8 \mathrm{~mm}$ ) responsivo ao $\mathrm{LH}$, capaz de ovular quando tratadas com hCG. Não existe na literatura trabalhos que tenham verificado sistematicamente o efeito da dose de hCG na ovulação do folículo dominante da primeira onda folicular. As doses utilizadas são bastante variáveis: $1000 \mathrm{UI}^{5}, 1500 \mathrm{UI}^{1,6,10}$, $2500 \mathrm{UI}^{13}, 3000 \mathrm{UI}^{3,4,7,12,14}, 3300 \mathrm{UI}^{11} \mathrm{e}$ $5000 \mathrm{UI}^{32}$. Os trabalhos que objetivaram a indução da ovulação do folículo dominante do dia 5 do ciclo estral utilizaram 3000UI $3,4,7,12$ e 3300 UI $^{11}$. Diaz et al. ${ }^{7}$ observaram a ovulação do folículo dominante em 100\% das novilhas, enquanto Santos et al. ${ }^{18}$ observou a ovulação do folículo dominante e a formação de um corpo lúteo acessório em $86,2 \%$ das vacas.

Determinou-se que em 5000UI de Pregnyl ${ }^{\circledR}$ há $0,92 \mathrm{mg}$ de proteínas, ou seja, em $0,1 \mathrm{mg}, 0,2 \mathrm{mg}$ e $0,3 \mathrm{mg}$ de Pregnyl® há respectivamente 543,5UI, 1086UI e 1630,4UI de hCG. Baseado nos dados acima. A partir de $0,2 \mathrm{mg}$ tais quantidades são suficientes para induzir a ovulação do folículo dominante da primeira onda no dia 5, conforme observado no presente experimento. Sugere-se que a atividade biológica tenha sido mantida após os procedimentos de purificação.

\section{Conclusão}

A técnica de cromatografia por afinidade utilizando uma matriz de Con-A foi eficiente para aumentar a concentração relativa do hCG a partir do produto comercial Pregnyl ${ }^{\circledR}$ e a amostra purificada manteve a capacidade de induzir a ovulação do folículo dominante da primeira proporcionalmente a quantidade utilizada. Assim, é possível elaborar-se um ensaio biológico para mensurar a atividade biológica do hCG, utilizando-se da propriedade dessa molécula de estimular a ovulação em vacas.

\section{Induction of ovulation in cows with affinity chromatography-purified Human Chorionic Gonadotropin (hCG)}

\section{Abstract}

Objective of the present study was to purify hCG contained in commercial preparation (Pregnyl ${ }^{\circledR}$ - Organon) by affinity
Key-words:

Human Chorionic

Gonadotropin

(hCG). 
chromatography and to evaluate ovulation rates in cows injected with

Cromatography. the purified hormone. A chromatography column containing Concanavalin-A. concanavalin-A sepharose (Con-A) matrix was equilibrated and one hundred thousand international units (UI) of Pregnyl $®$ were applied Ovulation. to the column. Fractions of $3,8 \mathrm{~mL}$ were collected $\left(4^{\circ} \mathrm{C}\right)$ every 5 minutes for $12,5 \mathrm{~h}$, to yield a total of 150 fractions. After fraction 76 , a column buffer containing $0,3 \mathrm{M} \alpha$-methylglicoside was added to the column. Protein concentrations were estimated by espectrophotometry $(280 \mathrm{~nm})$. Two peaks of absorbance were observed, between fractions 14 and 19, and fractions 90 and 100. Fractions 14-19 and 90-150 were sequentially grouped in pairs concentrated by ultrafiltration and analyzed by SDS-PAGE. The first peak of absorbance resulted from proteins contained in the commercial product, eluted from the column and not adsorbed by the Con-A matrix. The second peak represented proteins adsorbed by the column, especially hCG. The fractions containing hCG were grouped in a single sample and protein concentration was measured by the Lowry method. Cows in day 5 of the estral cycle, which had a dominant follicle larger than $8 \mathrm{~mm}$, were injected with $0,1,0,2$ or $0,3 \mathrm{mg}$ protein of the purificated sample. The ovulation rate 48 hours after treatment was $0 \%, 50 \%$ and $75 \%$, respectively. It was demonstrated that relative concentration of hCG can be increased by affinity chromatography and biological activity of purified hCG was satisfactory preserved.

\section{Referências}

1 PRICE, C. A.; WEBB, R. Ovarian response to hCG treatment during the oestrus cycle in heifers. Journal Reproduction and Fertility, v. 86, n. 1, p. 303-308, 1989.

2 BREUEL, K. F.; SPITZER, J. C.; HENRICKS, D. M. Systemic progesterone concentration following human chorionic gonadotropin administration at various times during the estrous cycle in beef heifers. Journal of Animal Science, v. 67, n. 6, p. 1564-1572, 1989.

3 SCHMITT, E. J. P.; et al. A cellular and endocrine characterization of the original and induced corpus luteum after administration of a gonadotropin-releasing hormone agonist or human chorionic gonadotropin or an agonist of gonadotropin-releasing hormone. Journal of Animal Science, v. 74, p. 1915-1929, 1996 a.

4 SCHMITT, E. J. P.; et al. Differential response of the luteal phase and fertility in cattle following ovulation of the first-wave follicle with human choruionic gonadotropin or a agonist of gonadotropin-releasing hormone. Journal of Animal Science, v. 74, p. 1074 1083, $1996 \mathrm{~b}$.

5 RAJAMAHENDRAN, R.; SIANANGAMA, P. C. Effect of human chorionic gonadotropin on dominant follicles in cows. Formation of accessory corpora lutea, progesterone production and pregnancy rates. Journal Reproduction and Fertility, v. 95, n. 2, p. 577-584, 1992.

6 FRICKE, P. M.; REYNOLDS, L. P.; REDMER, D. A.
Effect of human chorionic gonadotropin administred early in the estrous cycle on ovulation and subsequent luteal function in cows. Journal of Animal Science, v. 17 , n. 5, p. 1242-1246, 1993.

7 DIAZ, T.; et al. Human chorionic gonadotropininduced alterations in ovarian follicular dynamics during the estrous cycle of heifers. Journal of Animal Science, v. 76, n.7, p.1929-1936, 1998.

8 HARIADI, M.; BROOMFIELD, D.; WRIGHT, P. J. The synchrony of prostaglandin-induced estrus in cows was reduced by pretreatment with hCG. Theriogenology, v. 49, n. 5, p. 967-974, 1998.

9 MARQUES, M. O.; et al. Ovarian ultrasonography and plasma progesterone concentration in Bos taurus $x$ Bos indicus heifers adsministered different treatments on day 7 of the estrous cycle. 2002. Theriogenology, submitted.

10 MACHATKOVA, M.; et al. Developmental competence of bovine oocytes: effects of follicle and the phase of follicular wave on in vitro embryo production. Therigenology, n. 15, v. 61, p. 329-335, 2004.

11 SANTOS, J. E. P.; et al. Effect of human chorionic gonadotropin on luteal function and reproductive performance of high producing lactating Holstein dairy cows. Journal of Animal Science, v. 79, n. 11, p. 28812894, 2001.

12 THATCHER, W. W.; et al. Strategies to optimize reproductive efficiency by regulation o ovarian function. Domestic Animal Endocrinology, v. 23, n. 1-2, p. 243- 
254, 2002.

13 GEARY, T. W.; SALVERSON, R. R.; WHITTIER, J. C. Synchronization of ovulation using GnRH or hCG with the OvSynnch protocol in suckled beef cows. Journal of Animal Science, v. 79, n. 10, p. 2536-2541, 2001.

14 CASTILHO, C.; et al. Synchronization of ovulation in crossbred dairy heifers using gonadotropin-releasing hormone agonist, prostaglandin F2? and human chorionic gonadotrophin or estradiol benzoate. Brazilian Journal of Medical and Biological Research, v. 33, n. 1, p. 91-101, 2000.

15 THATCHER, W. W.; et al. New clinical uses of $\mathrm{GnRH}$ and its analogues in cattle. Animal Reproduction Science, v. 33, n. 1-4, p. 27-49, 1993.

16 PIERCE, J. G.; PARSONS, T. F. Glycoprotein hormones: structure and function. Annual Review of Biochemistry, n. 50, p. 465-495, 1981.

17 BOUSFIELD, G. R.; PERRY, W. M.; WARD, D. N. Gonadotropins, chemistry and biosynthesis. In: KNOBIL, E.; NEILL, J. D. The physiology of reproduction. 2. ed. New York: Raven Press, 1994. cap. 30 .

18 MANJUNATH, P.; SAIRAM, M. R. Bichemical, Biological, and Immunological properties of chemicaly deglycosylated human choriogonadotropin. The Journal of Biological Chemistry, v. 257, p. 7109-7115, 1982.

19 DICZFALUSY, E.; LORAINE J. A. An improved method for the bioassay of chorionic gonadotrophin. Acta Journal Endocrinology, v. 17, p. 58-73, 1954.

20 TAJIC, M.; BACIC, M. The human chorionic gonadotrophin bioassay by seminal vesicles in mice. Experientia, v. 25, n. 3, p.332-333, 1969.

21 ROBYN, C.; PETRUSZ, P.; DICZFALUSY, E. Follicle stimulating hormone-like activity in human chorionic gonadotrophin preparations. Acta Endocrinologica, n. 60, p. 137-156, 1969.

22 GIANNATTASIO, G.; LUGARO, G.; MANERA, E. Effects of the vehicle in the bioassay of human chorionic gonadotropin. Experientia, v. 15, n. 26, p. 1268, 1970. No abstract available.

23 JACOBS, M. M.; WARD, D. N.; GRIFFIN, A. C. A systematic analysis of the hCG augmentation assay for follicle stimulating hormone. Procedings of the Society for Experimental Biology and Medicine, v. 144, n. 1, p. 106-109, 1973. No abstract available.

24 LORAINE, J. A; LUNN, S. F. The effect of initial body weigth on the response of the rat to treatment with gonadotrophins. Acta Endocrinologica, n. 72, p. 218-225, 1973

25 SHAEFER, J. M.; WEIDENFELD, J. The effects of HCG, indomethacin, flufenamic acid and aspirin in the immature female rat. Journal of Reproduction and Fertility, v. 45, n. 2, p. 227-233, 1975.
26 RIPPEL, R. H.; JOHNSON, E. S. Inhibition of HCGinduced ovarian and uterine weight augmentation in the immature rat by analogs of GnRH. Procedings of the Society for Experimental Biology and Medicine, $v$. 152, n. 3, p. 432-436, 1976.

27 BERTAN, C. M.; CUNHA, P. M.; BINELLI, M. Evaluation of bioassays for measuring biological activity of Human Chorionic Gonadotropin (hCG). Brazilian Journal of Veterinary Research and Animal Science, 2004. submitted.

28 WALTON, J. S.; et al. Effects of progesterone and human chorionic gonadotrophin administration five days pos-insemination on plasma and milk progesterone and pregnancy rates of normal and repeat breeder dairy cow. Canadian of Journal Veterinary Research, v. 54 n. 3 , p. $305-308,1990$

29 RICHARDS, M. W.; SPITZER, J. C.; WARNER, M. B. Effect of varying levels of pospartum nutrition and body condition at calving on subsequent reproductive performance in beef cattle. Journal of Animal Science, v. 62 , n. 2, p. 300-306, 1986.

32 HOWARD, H. J.; BRITT, J. H. Prostaglandin F-2 alpha causes regression of an hCG-induced corpus luteum before day 5 of its lifespan in cattle. Journal Reproduction and Fertility, v. 90, n. 1, p. 254-253, 1990.

$30 \mathrm{XU}, \mathrm{Z}$;; et al. Expression of follicle-stimulating hormone and luteinizing hormone receptors messenger ribonucleic acids in bovine follicles during the first follicular wave. Biology of Reproduction, v. 53, p. 951-957, 1995.

31 GINTHER, O.J.; et al. Selection of the dominant follicle in cattle. Biology of Reproduction, v. 55, p. 1187-1194, 1996. 